\title{
An unusual case of hepatic abscess
}

Robert Tambay MD, Jean Côté MD, Anne-Marie Bourgault MD, Jean-Pierre Villeneuve MD

R Tambay, J Côté, A-M Bourgault, J-P Villeneuve. An unusual case of hepatic abscess. Can J Gastroenterol 2001;15(9):615-617. A case of recurring primary hepatic actinomycosis is reported. A 50 -year-old man presented with fever, weight loss and multiple hepatic masses. A diagnosis was obtained by cytological examination of a biopsy sample taken from the largest hepatic mass, which revealed the presence of Actinomyces species. The patient was treated with penicillin for 12 months and did well. Seven years later, he presented with similar symptoms but with a single large liver mass and a pulmonary infiltrate in the right lower lobe. Liver biopsy showed an inflammatory pseudotumour, and lung biopsy showed the presence of Actinomyces species. Again, the patient was treated with penicillin. Five months later, the patient was doing well, and a follow-up computed tomography scan showed partial regression of the hepatic pseudotumour. This case indicates that hepatic actinomycosis can recur several years after an appropriate treatment and stresses the need for careful follow-up in such patients.

\section{Cas rare d'abcès hépatique}

RESUME : On signale ici un cas de récurrence d'actinomycose hépatique primaire chez un homme de 50 ans, présentant un état fébrile, une perte de poids et de multiples masses hépatiques. Le diagnostic a été obtenu après examen cytologique d'une biopsie prélevée sur la masse hépatique la plus volumineuse qui a confirmé la présence du genre Actinomyces. Le patient a été traité au moyen de pénicilline pendant 12 mois et a bien récupéré. Sept ans plus tard, il s'est présenté pour des symptômes similaires, mais une seule masse hépatique volumineuse est visible, de même qu'un infiltrat pulmonaire au lobe inférieur droit. La biopsie hépatique a révélé la présence d'une pseudotumeur inflammatoire et la biopsie pulmonaire, la présence du genre Actinomyces. Encore une fois, le patient a été traité au moyen de pénicilline. Cinq mois plus tard, il se portait bien et une scintigraphie de suivi a confirmé la régression partielle de la pseudotumeur hépatique. Ce cas confirme que l'actinomycose hépatique peut récidiver plusieurs années après un traitement approprié et rappelle la nécessité d'exercer un suivi étroit chez de tels patients.

Key Words: Actinomyces; Hepatic actinomycosis; Inflammatory pseudotumour; Liver abscess

A ctinomycosis is a chronic suppurative disease characterized by the formation of abscesses, draining sinuses and abundant granulation tissue, and by the appearance of 'sulphur granules' in the discharge of involved tissues. Three regions of the body in humans are most frequently involved: the cervicofacial area in $60 \%$ of cases, the thorax in $20 \%$ of cases and the abdomen in $20 \%$ of cases (1). Bradshaw is given credit for first describing a patient with abdominal actinomycosis in 1846. This English surgeon noted the pres- ence of a mass in the right iliac fossa that slowly grew over a two-year period, culminating in an abscess that was drained, only to recur after treatment with potassium iodide. The causative organism was unknown in Bradshaw's time. In 1877, Bollinger described the infective agent, thought to be a fungus responsible for actinomycosis. In the same year, Harz described the organism as filaments radiating from a central mass; the name Actinomyces, literally 'fungus with rays', was coined (2). It is now known that Actinomyces

Service d'hépatologie, de pathologie et de microbiologie, Hôpital Saint-Luc, Centre Hospitalier de l'Université de Montréal, Montréal, Québec Correspondence and reprints: Dr Jean-Pierre Villeneuve, Liver Unit, Centre de recherche du CHUM, Hôpital Saint-Luc, 264 east René-Lévesque blvd, Montréal, Québec H2X 1P1. Telephone 514-890-8000 ext 35706, fax 514-412-7314, e-mail hepato.saint-luc@sympatico.ca Received for publication May 23, 2000. Accepted February 6, 2001 


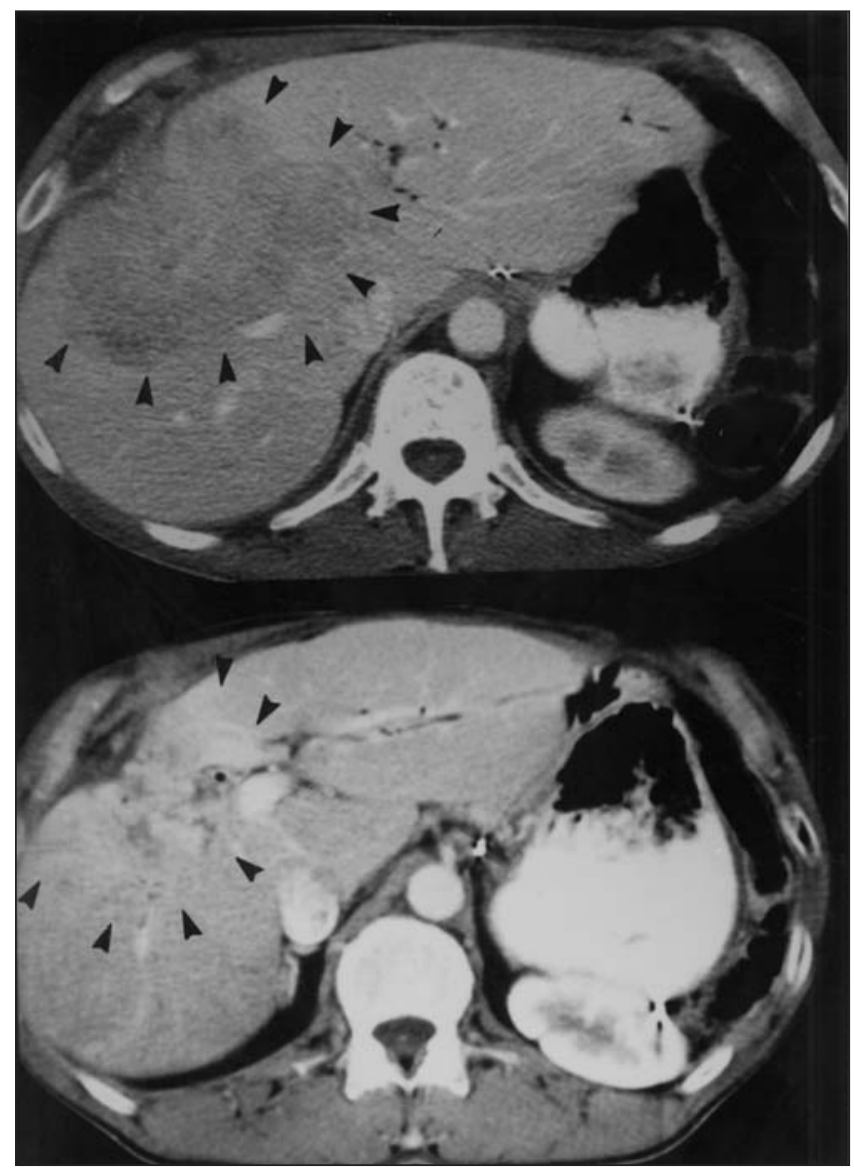

Figure 1) Top Computed tomography scan showing a large mass in the liver, which was found to be an inflammatory pseudotumour on biopsy. Bottom Five months later, the mass had clearly regressed with penicillin treatment alone

species are Gram-positive bacteria that are slow-growing, anaerobic, filamentous and exquisitely sensitive to penicillin.

In this report, we present a case of recurring hepatic actinomycosis and consider novel elements in the natural history and management of this rare disease.

\section{CASE PRESENTATION}

A 50-year-old man presented with a one-week history of intermittent right upper quadrant (RUQ) pain. Fourteen years before admission to the hospital, the patient had undergone total pancreatectomy, splenectomy, cholecystectomy and choledochojejunostomy for chronic painful alcoholic pancreatitis, resulting in pancreatic exocrine insufficiency and diabetes. He had abstained from alcohol since then. Two days before admission to the hospital, the patient developed fever with night sweats and constant RUQ pain. Physical examination revealed a normal blood pressure, with mild tachycardia and a temperature of $38^{\circ} \mathrm{C}$. Oral and dental hygiene were good. There was RUQ tenderness. There were no stigmata of chronic liver disease. The examination was otherwise unremarkable. The white blood cell count was $16,000 / \mathrm{mm}^{3}$, with a left shift. He had normocytic normochromic anemia, with a hemoglobin concentration of $101 \mathrm{~g} / \mathrm{L}$ and an increased platelet count $\left(647,000 / \mathrm{mm}^{3}\right)$. Urinalysis was normal, as were blood urea and creatinine levels. The serum bilirubin level was $8 \mu \mathrm{mol} / \mathrm{L}$, but the alkaline phosphatase level was increased at $304 \mathrm{U} / \mathrm{L}$ (normal 20 to $89 \mathrm{U} / \mathrm{L}$ ). Values for aspartate aminotransferase and alanine aminotransferase were normal. The prothrombin international normalized ratio was 1.1, and the albumin concentration was $24 \mathrm{~g} / \mathrm{L}$. The gamma globulin concentration was increased at $18.6 \mathrm{~g} / \mathrm{L}$ (normal 8.1 to $15.0 \mathrm{~g} / \mathrm{L}$ ). Glycated hemoglobin was increased at $8.9 \%$ (normal 4.2\% to 5.9\%). Alpha-fetoprotein and carcinoembryonic antigen levels were within the normal range. Abdominal ultrasound and a computed tomography (CT) scan revealed multiple liver masses that showed intense uptake on a subsequent ${ }^{67}$ gallium scan. Upper and lower gastrointestinal studies failed to show evidence of malignancy. The fever dropped with cerufoxime, and the patient was sent to the authors' institution for further work-up. Both abdominal ultrasound and CT scan demonstrated three masses in the liver (two in segment 7 and one in segment 4 , the largest measuring $6 \times 7 \mathrm{~cm}$ in segment 7 and the other two measuring $3 \times 3 \mathrm{~cm}$ ). There was no ascites or lymphadenopathy. An ultrasound-guided biopsy of the largest mass showed evidence of chronic inflammation and fibrosis. Cytological examination of a biopsy sample revealed the presence of numerous Actinomyces colonies. Viral and bacterial cultures were otherwise negative, and no acid-fast bacilli were identified. The patient was treated with penicillin intravenously for six weeks followed by oral penicillin for 12 months and did well; he was not seen after that period.

Seven years later, the patient presented with a similar clinical picture; abdominal CT scan revealed a solitary hepatic mass saddling segment 4,8 and 5 , and measuring $9 \mathrm{~cm}$ in its largest diameter (Figure 1, Top). Chest $\mathrm{x}$-ray showed a right lower lobe infiltrate. A thoracic CT scan showed bilateral, small, solid nodules and a parenchymal infiltrate of the right lower lobe. A liver biopsy revealed a hepatic pseudotumour, and a thoracoscopic lung biopsy showed abscesses containing aggregates of Actinomyces species (Figures 2 and 3). Cultures were negative for Actinomyces species and the patient was again treated with penicillin intravenously for six weeks followed by oral penicillin. Five months later, the patient was doing well, and a follow-up CT scan showed partial regression of the hepatic pseudotumour (Figure 1, Bottom).

\section{DISCUSSION}

In the first published series of 122 cases of abdominal actinomycosis, $89 \%$ of cases followed an acute abdominal illness, most often acute appendicitis (1). The infection became apparent several weeks to months later. In a study of 181 subjects with actinomycosis, debilitating illness and surgical procedures, thought to predispose patients to infection, were found in only $45 \%$ of cases (3). Actinomyces species are not found outside the bodies of animals or humans. They 


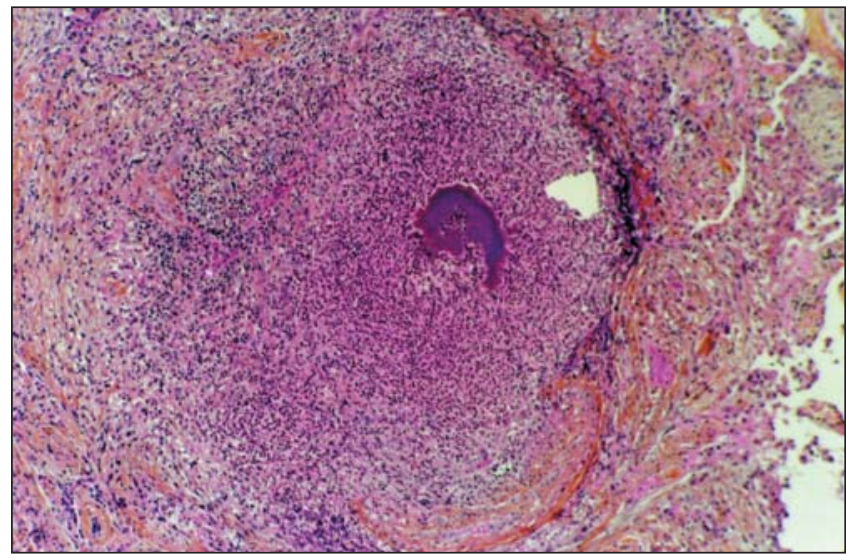

Figure 2) Actinomycotic abscess in the lung containing colonies of Actinomyces species in its centre (hematoxylin-saffron-phloxine stain)

are endogenous to the oral cavity and tonsillar crypts. In healthy individuals, the gastrointestinal tract does not harbour these organisms (2). It seems that infection probably begins when aggregates of Actinomyces organisms reach damaged tissue following aspiration or injection of oral debris into tissue. Why the disease may manifest years after inoculation is unknown (4). Previous sensitization and resistance of the host, and virulence of the various strains may play a role in the production of disease (1). An individual may harbour the infection for years until a state of immunosuppression allows it to spread and become manifest. Abdominal actinomycosis occurring in an asplenic individual has not been reported. Diabetes mellitus as a predisposing condition has been described (5). Liver involvement is reported in 5\% of patients with actinomycosis and in $15 \%$ of cases with abdominal involvement. Fever and RUQ pain are the usual presenting features (5-9). Liver biopsy typically reveals an inflammatory infiltrate within a fibrous stroma $(8,10)$. Hematogenous spread is believed to be uncommon, and it is thought that the disease spreads by direct extension of the infectious process (1). Indeed, hepatic actinomycosis infiltrating the right lung has previously been described (11).

The present case shows an unusual evolution of the disease, because it relapsed seven years after appropriate antibiotic therapy. A five-year follow-up of two patients with no recurrent disease has previously been noted, but information regarding follow-up is generally lacking in published series (5). It is hypothesized that the initial treatment failed to eradicate the infection, which remained quiescent for many years only to re-emerge more aggressively. Reasons for failure to eradicate the Actinomyces species after the initial 12-month course of treatment are unclear. The patient said that he had been compliant to the medication, and there are no published reports of penicillin resistance

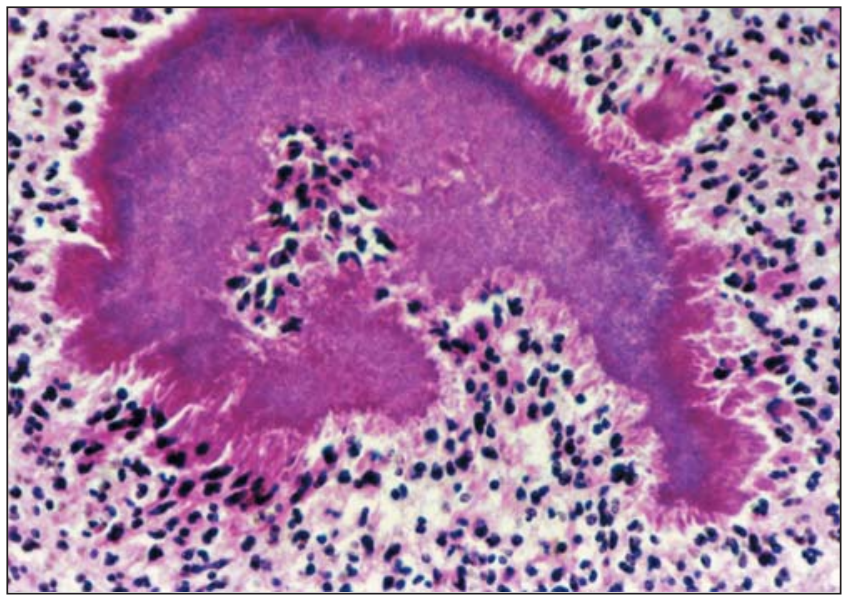

Figure 3) High power view of a colony of Actinomyces species showing filaments radiating from a central mass

among Actinomyces species. In some cases, treatment should possibly be continued beyond the usually recommended six to 12 months of treatment. Alternatives to prolonged penicillin treatment include the addition of a second antimicrobial agent such as clindamycin or doxycyclin, or surgical resection.

\section{SUMMARY}

Actinomycotic liver abscess is a rare entity, the natural history of which needs to be further defined. That actinomycosis might actually be an incurable chronic disease is thought-provoking and stresses the need for careful followup in these patients.

\section{REFERENCES}

1. Putman HC, Dockerty B, Waugh JM. Abdominal actinomycosis: an analysis of 122 cases. Surgery 1950;28:781-800.

2. Berardi RS. Abdominal actinomycosis. Surg Gynecol Obstet 1979;149:257-66.

3. Brown JR. Human actinomycosis; a study of 181 subjects. Hum Pathol 1973;4:319-30.

4. Meade RH. Primary hepatic actinomycosis. Gastroenterology 1980;78:355-9.

5. Weese WC, Smith IM. A study of 57 cases of actinomycosis over a 36-year period. Arch Intern Med 1975;135:1562-8.

6. Jonas RB, Brasitus TA, Chowdhury L. Actinomycotic liver abscess; case report and literature review. Dig Dis Sci 1987;32:1435-7.

7. Bhatt BD, Zuckerman MJ, Ho H, Polly S. Multiple actinomycotic abscesses of the liver. Am J Gastroenterol 1990;85:309-10.

8. White JE, Chase CW, Kelley JE, Brock WB, Clark MO. Inflammatory pseudotumor of the liver associated with extrahepatic infection. South Med J 1997;90:23-9.

9. Sugano S, Matuda T, Suzuki T, et al. Hepatic actinomycosis; case report and review of the literature in Japan. J Gastroenterol 1997;32:672-6

10. Vargas C, Gonzalez C, Pagani W, Torres E, Fas N. Hepatic actinomycosis presenting as liver mass: case report and review of the literature. PR Health Sci J 1992;11:19-21.

11. Kasano Y, Tanimura H, Yamaue H, Hayashido M, Umano Y. Hepatic actinomycosis infiltrating the diaphragm and right lung. Am J Gastroenterol 1996;91:2418-20. 


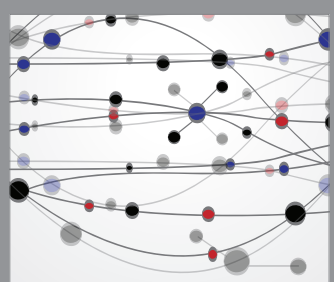

The Scientific World Journal
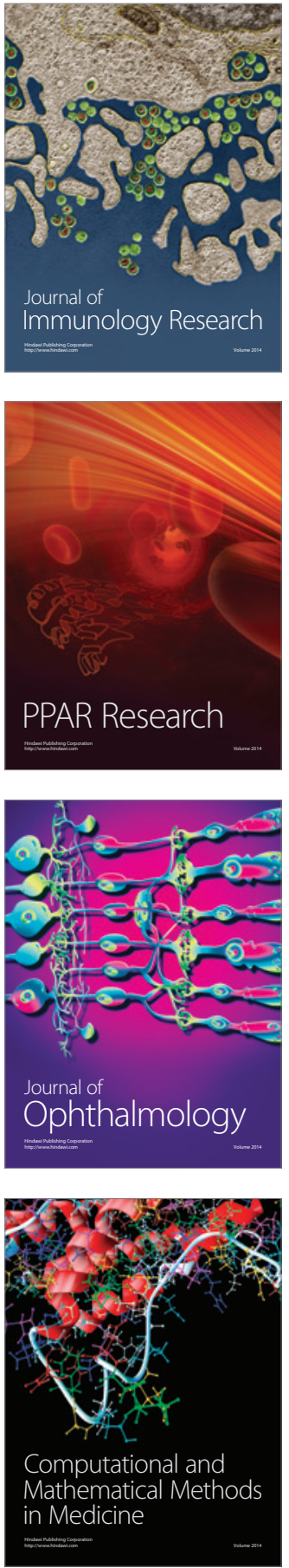

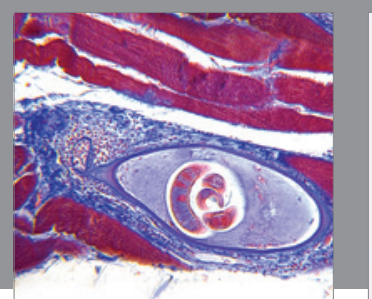

Gastroenterology Research and Practice

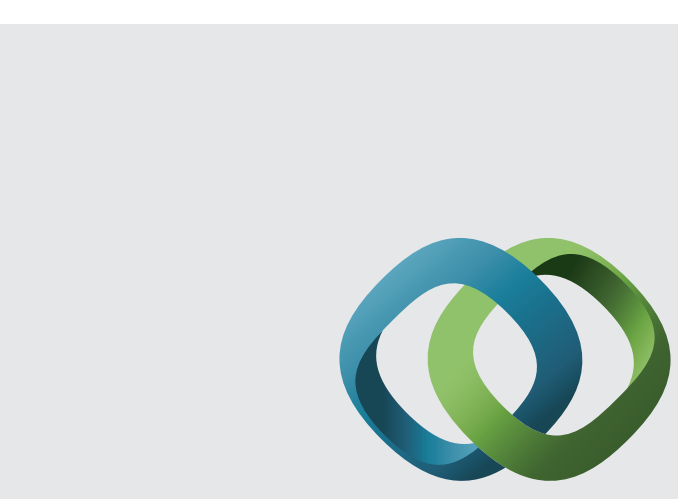

\section{Hindawi}

Submit your manuscripts at

http://www.hindawi.com
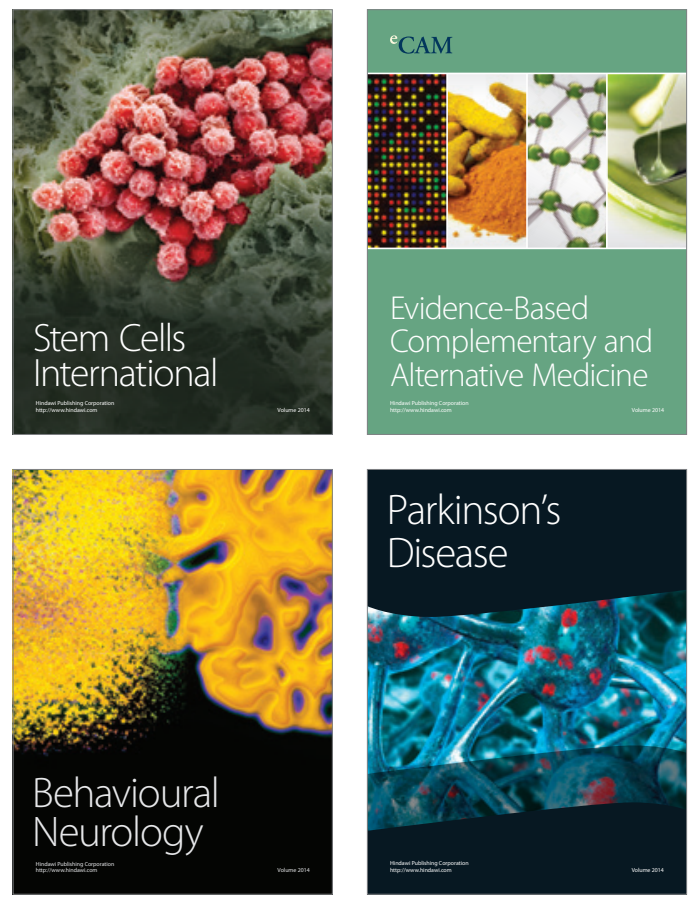
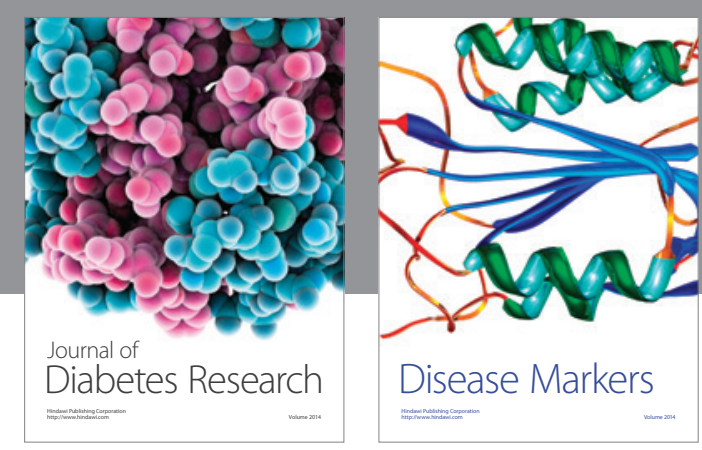

Disease Markers
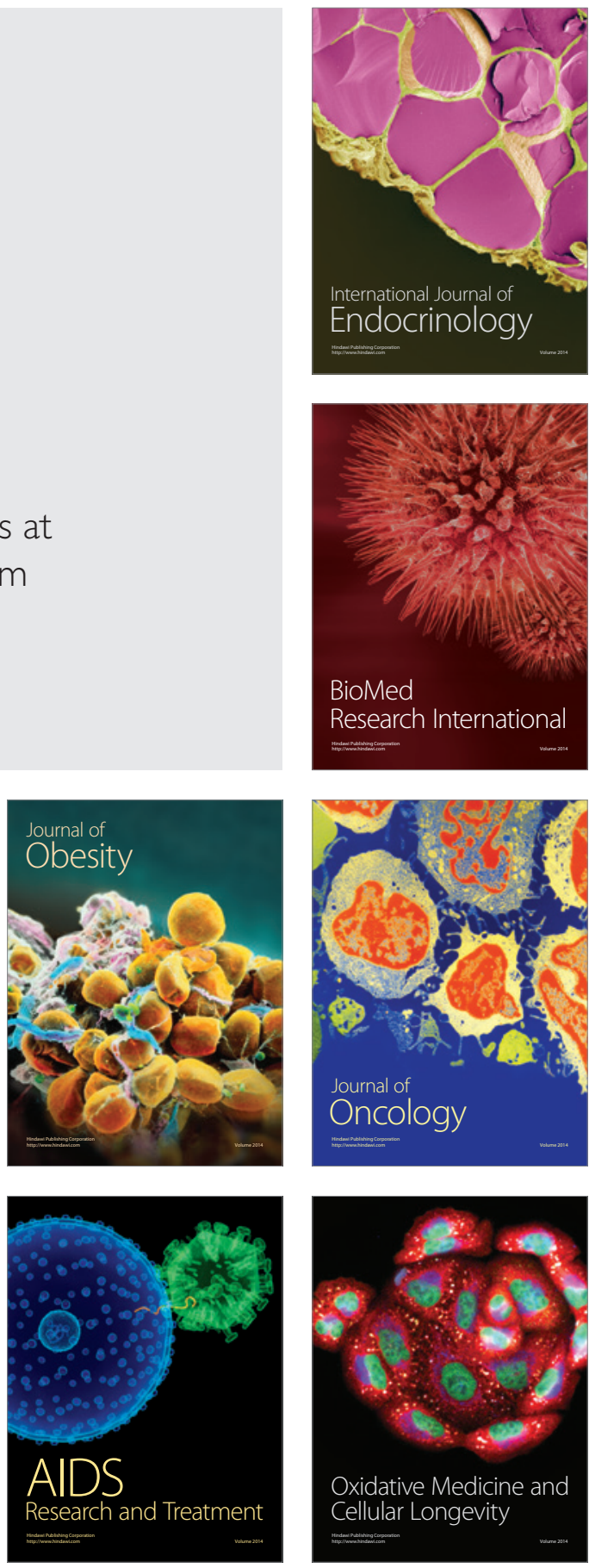